\title{
ANNOTATION
}

\section{Official and Industrial Encouragement of Research}

There are many problems of photography which can only be solved by a thorough knowledge of the physiology of vision: Apart from the question of the deleterious effect of radiations emanating from the sources of light which are used in the production of pictures, and especially of cinema films-a subject to which we have referred before (this Journal, Vol. V, 1921, p. 460) - the perfection of a photographic picture depends upon gradations of light and shade which conform as nearly as possible to the gradations as seen by the normal eye. The ordinary photographic film has a curve of sensitivity which corresponds with the actinicity of the spectral radiation and this, as is well known, increases rapidly towards the violet end of the spectrum, and still more rapidly in the contiguous ultra-violet region. The ultra-violet radiation produces no luminous impression upon the eye, and consequently the gradations of light and shade in a photograph taken on an ordinary plate give but an inadequate representation of the scene as viewed. By the use of suitable dyes the sensitivity of the film can be considerably increased in the most luminous portion of the spectrum (orthochromatic plates) and can be materially increased even in the almost inactinic red region (panchromatic plates). By the use of appropriate filters still further modifications can be introduced. The subject is further complicated by the divergence in the energy distribution of the radiation emitted by sunlight and the various forms of artificial illumination. Hitherto the public have been satisfied with very mediocre results, and the advances made by photographers have been in large part empirical. It is well known, for instance, that, although increase in actinicity is brought about by the use of light sources rich in ultra-violet radiation, these ultra-violet rays are almost completely absorbed by the glass lenses used in the photographic camera. It is only by accurate scientific investigation that the properties of light sources, lenses and films can be satisfactorily determined; and when all this has been accomplished there yet remains the accurate correlation of the results with the sensitivity of the retina. Very exhaustive investigations of this nature have been initiated by Loyd A. Jones* in the Research Laboratory of the Eastman Kodak Company. Apart from the special interest of this research to photographers, they are of great value to all who are interested in the physiology of vision; for such investigations nearly always reveal gaps in our knowledge of the reactions of the eye to various stimuli.

*Communication No. 135 from the Research Laboratory of the Eastman Kodak Co. (abstracted in The Illuminating Engineer, xv., pp. 247, 271, 1922.). 
Loyd Jones is already known as the author of a valuable research on the discrimination of hue in the spectrum, a research which confirms the observations of Steindler and others, and is of the greatest theoretical importance to physiologists, psychologists and ophthalmologists. Our knowledge of heterochromatic photometry by the flicker method, which is also of profound importance in the theory of vision, has been developed and put upon a sound scientific basis by the exhaustive experiments of Ives, Nutting, Luckiesh, Troland and others. Nearly all this work has been done in the research laboratory of the National Lamp Association, Cleveland, Ohio, or the Nela (Lamp) research laboratories. Scientific results of the greatest value have followed researches initiated by the Bureau of Standards at Washington. It is a humiliating, but undoubted fact that Industrial Corporations in the United States are far more alive to the advantages of scientific research than are the corresponding bodies in Great Britain. The lethargy from which we were aroused during the war seems to have fallen upon us again. So far as encouragement by the Government is concerned the Medical Research Council and the Industrial Fatigue Board have succeeded in evading the axe, and are carrying on most admirable work. The National Institute of Industrial Psychology is also carrying on a financially precarious existence under the able supervision of Dr. C. S. Myers, but requires far more adequate support than it is receiving. We are grateful to our transatlantic rivals for the excellent research work which they are doing. In common with the rest of the world we are sharing the benefits. It is as much a matter of honour that we should make an effort to repay this debt as the more material debt which Englishmen are too proud to attempt to evade.

\section{ABSTRACTS}

\section{I.-OCULAR PHLYCTENULAE AND TRACHEO- BRONCHIAL ADENOPATHY}

Weekers and Colmant (Liège).-Ocular phlyctenulae and tracheo-bronchial adenopathy. (Phlyctènes oculaires et adénopathie trachéo-bronchique.) Arch. d'Ophtal., February, 1922.

Weekers has on several occasions given expression to his belief that the subjects of phlyctenular kerato-conjunctivitis are tuberculous. He recognizes that this view is not universally accepted. It is true that the association is usually with tuberculosis of a quiet and torpid type compatible with apparent good health. In 